\title{
ORÇAMENTO PROGRAMA NO SERVIÇO DE ENFERMAGEM
}

\author{
Irmã Maria Adjutrix * \\ Irmã Dulce Oliveira Azevedo ** \\ Terezinha Aguiar Viana ** \\ Sanhana Toniello **
}

INTRODUÇÃO:

Considerando o hospital uma empresa, deve este necessariamente ocupar-se com suas despesas e suas entradas financeiras, visando alcançar o equilíbrio entre as suas necessidades e seus recursos disponíveis.

Aceitando a afirmação que $60-67 \%$ do pessoal hospitalar cabe ao serviço de enfermagem, é lógico que este serviço, como o maior dentro do hospital, necessitará provavelmente os maiores recursos para poder dar uma assistência adequada aos pacientes.

Muitas vezes, a cúpula administrativa se acha diante de uma difícil problemática em precisar decidir sobre a distribuição dos seus recursos. Onde achará um meio, uma medida que lhe dará claramente a solução, sem prováveis erros? Onde achará o guia que lhe mostrará o caminho certo nos passos administrativos da análise lógica, baseada em dados objetivos das verdadeiras necessidades da grande complexidade dos diversos serviços que formam a enorme máquina hospitalar?

O orçamento-programa nas suas diversas fases é sem dúvida um les melhores instrumentos da racionalização do sitema administrativo dos seus serviços e em especial do serviço de enfermagem, dando-lhe a possibilidade de um planejamento das suas atividades, baseado nos recursos disponíveis do hospital.

Pela análise lógica da elaboração do sistema de prioridade, que ¿ uma das fases do orçamento-programa do serviço de enfermagem,

* Diretora do Serviço de Enfermagem do HSPE - SP.

** Enfermeiras do HSPE - SP. 
o hospital alcançará a melhor utilização possível dos seus recursos e consequentemente a maior economia.

\section{DEFINIÇÃO:}

Orçamento-programa é um método sistemático de levantar e analisar dados do passado e do presente, e, baseando-se neste levantamento, estabelecer planos para o futuro, mostrando o caminho de sua execução, exigindo recursos humanos e materiais numa expressão financeira.

Orçamento-programa no serviço de enfermagem significa progragramar as atividades de enfermagem, segundo as suas prioridades, $€$ necessidades, inclusive de recursos financeiros, para a execução do programa.

\section{OBJETIVOS DO ORÇAMENTO-PROGRAMA DO SERVIÇO DE ENFERMAGEM}

São diversos os objetivos de um orçamento-programa do serviço de enfermagem. Citamos os mais imprtantes:

1. Obter a maior economia possível e prevenir deficiência financeira no desenvolvimento das suas atividades.

2. Demonstrar à cúpula administrativa do hospital o custo real das suas atividades.

3. Servir como meio de informações referentes às suas atividades.

4. Prever as necessidades de pessoal e material para um bom funcionamento do serviço.

5. Apurar o pessoal e material em excesso.

6. Avaliar a conservação e durabilidade do material permanente e equipamentos, usados na enfermagem.

7. Estabelecer a cota anual do material de cosumo, necessário para o serviço.

\section{FASES A OBSERVAR NA ELABORAÇÃO DO CRÇAMENTO-PROGRAMA}

$\mathrm{Na}$ elaboração do orçamento-programa no serviço de enfermagem devemos observar as seguintes fases:

1. Levantamento de dados que revelem a situação do serviço de enfermagem em termos do passado e do presente.

2. Análise e diagnóstico da situação atual. 
3. Apresentação de soluções referentes aos problemas levantados.

4. Estabelecimento das prioridade das necessidades encontradas.

5. Definição dos objetivos da programação das atividades a serem realizadas.

6. Programação das atividades a realizar.

7. Determinação das necessidades de recursos:

a) humanos

b) materiais (material permanente, equipamentos, material de consumo)

c) serviços de terceiros

8. Cálculo das necessidades financeiras para prover recursos humanos, materiais e serviços de terceiros.

\section{1. ${ }^{\mathrm{a}}$ FASE:}

Levantamento de dados que revelem a situação do serviço de enfermagem em termos do passado e do presente.

Através de uma minuciosa e real estatística comparativa das atividades realizadas no serviço de enfermagem nos anos passados e no ano presente, apresenta-se nesta fase a situação do serviço com todas as suas lutas e dificuldades, como também com suas vitórias e metas do futuro.

A diretoria administrativa do hospital vê neste levantamento o serviço de enfermagem em suas luzes e sombras, conscientiza-se dos grandes ideais que devem ser alcançados, como também das barreiras que precisam ser vencidas.

Mostra-se nesta fase a situação do serviço de enfermagem em relação ao pessoal profissional e não profissional do ponto de vista qualitativa e quantitativamente. Tem-se a oportunidade de revelar a. existência do pessoal ocioso e suas diversas razões, as falhas na assistência aos pacientes, provindas em parte pelo déficit do pessoal.

Cita-se o número e o estado do material permanente e equipamentos usados no serviço de enfermagem. Este levantamento deve ser feito na base de inventário, mostrando o material existente, sua localização e sua provável durabilidade, baseando-se em dados bem objetivos.

\section{2. ${ }^{\mathrm{a}}$ FASE:}

Análise e diagnóstico da situação atual:

A partir dos dados levantados no estudo anterior, estabelece-se c, diagnóstico da situação atual, esclarecendo os porquês desta situação, mostrando as prováveis causas que provocaram tal estado. 


\section{3. ${ }^{\mathrm{a}}$ FASE:}

Apresentação de soluções, referentes aos problemas levantados:

Se temos a ousadia e a coragem de levantar toda a problemática do serviço e revelar uma situação que clama por uma cura ou melhoramento, devemos ter também a capacidade e retidão para dar soluções convenientes. Não se devem levantar problemas ou criticar algo, sem da mesma maneira mostrar o remédio para curar as chagas, apontar o caminho que conduz à meta a alcançar.

Diante de uma verídica situação e diagnóstico do atual serviço de enfermagem, torna-se logicamente funcional propor e analisar soluções convenientes; podem ser apresentadas diversas soluções para l:ma mesma situação que deve ser melhorada ou totalmente mudada.

\section{4. ${ }^{\mathrm{a}}$ FASE:}

Estabelecimento das prioridades das necessidades encontradas:

Coloca-se nesta fase todos os problemas levantados segundo as suas prioridades com as propostas de soluções.

É um trabalho simples e rápido, sem grandes dificuldades.

\section{5. ${ }^{\mathrm{a}}$ FASE:}

Definição dos objetivos da programação das atividades a serem realizadas segundo a fase anterior:

Qualquer solução proposta deve estabelecer os seus objetivos. expressados com clareza e bem definidos de acordo com a prioridade dos problemas a serem resolvidos.

\section{FASE:}

Programação das atividades a realizar:

Para se alcançar a meta de cada objetivo estabelecido em relação às propostas de soluções, surge a necessidade de planejamento das atividades a serem executadas, observando os diversos planos de ação. Descreve-se aqui cada atividade, passo por passo, calculondo o tempo necessário de sua execução.

\section{7.. FASE:}

Determinação das necessidades de recursos:

Não se realiza trabalho algum, sem ter em mãos os devidos recursos para seu desenvolvimento. 
Distinguimos em geral os seguintes recursos:

Recursos humanos;

Recursos materiais;

Recursos para serviços de terceiros.

Recursos humanos:

Estes recursos devem ser apresentados:

a) em termos de quantidade;

b) em níveis de categoria funcional;

c) com o provável tempo de utilização (diário, mensal ou anual).

Justifica-se claro e objetivamente a necessidade destes recursos que podem ser por aumento de serviço, baseando-se nos dados da estatística levantada na $1 .^{\mathrm{a}}$ fase ou por abertura de novas unidades, e novas programaçōes. Usa-se o método comparativo em gráficos ou a simples mostragem numérica em colunas:

a) unidades de trabalho;

b) número do pessoal previsto;

c) número do pessoal existente;

d) número do pessoal em falta;

e) os diversos anos.

\section{Recursos materiais:}

Determinamos neste ítem a necessidade de material de consumo, material permanente e equipamentos, justificando as suas necessidades.

Leva-se em consideração na elaboração deste passo a qualidade de cada material e o porquê de sua escolha, evitando preferência pessoal, unicamente baseando-se na lógica e objetividade de testes ou experiências.

Para facilitar este trabalho tão penoso, é aconselhável que o serviço de enfermagem tenha no seu arquivo:

a) os mapas do material de consumo de cada unidade, organizados alfabeticamente e com a cota mensal fixada que deve ser controlada e periodicamente reavaliada, geralmente de três em três meses. Tais mapas dão à direção do serviço de enfermagem a possibilidade de um controle rigoroso, visando a maior economia possível do próprio serviço;

b) fichário global do material permanente e equipamentos, organizado alfabética e numericamente com referência à sua localização. 
Recursos para serviços de Terceiros:

Neste ítem devem ser identificados os trabalhos feitos por firmas contratadas, por exemplo para manutenção e conservação de aparelhos especiais usados no serviço de enfermagem.

\section{FASE:}

Cálculo das necessidades financeiras em relação às necessidades de recursos humanos, materiais e serviços de terceiros

Os recursos mencionados na fase anterior, somente poderão ser alcançados se houver possibilidade de um financiamento, que nesta fase deve ser calculado da seguinte maneira:

a) Recursos financeiros ou verba necessária para a cobertura rias necessidades em material humano:

para o pessoal existente;

para o pessoal a ser admitido.

b) Recursos financeiros ou verba necessária para a cobertura das necessidades em matetrial de consumo.

c) Recursos financeiros ou verba necessária para a cobertura das necessidades em material permanente e equipamentos.

d) Recursos financeiros ou verba necessária para a cobertura de serviços de terceiros.

\section{VANTAGENS:}

Apresentando anualmente o orçamento-programa desta maneira, não há dúvida, que surjam grandes vantagens em relação ao serviço de enfermagem:

1. A cúpula administrativa se conscientiza das atividades globais do serviço, e nota a organização e capacidade administrativa que revela o orçamento-programa.

2. Há melhor aproveitamento dos recursos e possibilidade da c.eterminação de meios financeiros em bases mais realistas e o serviço de enfermagem não fica desta maneira esquecido ou colocado em último plano.

3. O serviço de enfermagem tem mais facilidade e possibilidade de verificar periodicamente se os seus objetivos foram atingidos.

4. Permite a realização e execução dos trabalhos com maior eficiência, segurança e tranquilidade, pois sabe-se de antemão, quais cs objetivos, quais os recursos autorizados para a realização das suas atividades. 
5. Permite demonstrar a economia que o serviço de enfermagem está oferecendo ao hospital sem prejudicar ou diminuir a assistência aos pacientes, mas pelo contrário, a mesma é melhorada.

\section{CONCLUSÃO:}

Concluindo, achamos conveniente e necessário que o serviço de enfermagem de qualquer hospital, seja este de grande ou pequeno porte, introduza a elaboração do orçamento-programa anual, uma atividade básica e necessária para o planejamento de suas atividades do ano vindouro, alcançando desta maneira maior segurança eficiência e harmonia no serviço.

\section{BIBLIOGRAFIA :}

1. FARIA, A. Nogueira de - Organização de Empresas - $1 .^{\circ}$ volume $3 .^{\mathrm{a}}$ ed. 1968 - Disribuidora Record, São Paulo.

2. GOVERNO DO ESTADO DE SĀO PAULO, SECRETARIA DA FAZENDA - Orçamento-Programa, texto programado, São Paulo, 1968. 